\title{
ASSESSMENT OF THE EFFECTS OF AIR POLLUTANTS ON BLOOD GLUCOSE CONTROL IN PATIENTS WITH TYPE 2 DIABETES
}

\author{
Amin Esmaeilzadeh ${ }^{1}$, Mahmoud Reza Delavar $^{2, *}$, Ensieh Nasli-Esfahani ${ }^{3,4}$ \\ ${ }^{1}$ MSc. student, GIS Dept., School of Surveying and Geospatial Engineering, College of Engineering, University of Tehran, Tehran, \\ Iran - esmaeilzade.amin@ut.ac.ir \\ ${ }^{2}$ Center of Excellence in Geomatic Eng. in Disaster Management, School of Surveying and Geospatial Eng., College of Engineering, \\ University of Tehran, Tehran, Iran - mdelavar@ut.ac.ir \\ ${ }^{3}$ Endocrinology and Metabolism Research Center, Endocrinology and Metabolism Clinical Sciences Institute, Tehran University of \\ Medical Sciences, Tehran, Iran \\ ${ }^{4}$ Endocrine \& Metabolism Research institute Tehran university of medical Sciences - n.nasli@ yahoo.com
}

Commission IV, WG IV/3

KEY WORDS: Air Pollution, T2DM, HbA1c, SDSS, Epidemiology, Smart Health

\begin{abstract}
Smart care is one of the elements of smart city, which has attracted the attention of many scholars to identify threats to the community's health. Air pollution has a significant contribution to diseases development such as type 2 diabetes, which is a major component of the global disease burden. The objective of this study is to investigate the effect of exposure to air pollutants such as $\mathrm{NO}_{2}, \mathrm{PM}_{2.5}$, and $\mathrm{PM}_{10}$ during 2016 on blood glucose control in Type 2 diabetic patients living in Tehran, capital of Iran. In this study, 124 diabetic patients of type 2 and partial correlation, odds ratio, and one-way Analysis of Variance have been considered to determine the effect of pollutants on the control of blood glucose in the patients. The results of this study verified that a significant positive correlation exists between $\mathrm{NO}_{2}$ and blood glucose in women $(\mathrm{r}=0.43$; $\mathrm{p}$-value $<0.001)$. There was also a relatively low but significant correlation in the female group between $\mathrm{PM}_{2.5}$ and blood glucose have been identified $(\mathrm{r}=0.27 ; \mathrm{p}$-value $=0.033)$. No significant correlation was found between pollutant $\mathrm{PM}_{10}$ and blood glucose in the patients. It is noteworthy that no correlation was found in the men's group for any of the pollutants.
\end{abstract}

\section{INTRODUCTION}

Diabetes mellitus doubles the risk of cardiovascular diseases and is the seventh leading cause of global mortality in 2016 (Coogan et al. 2016). Type 2 diabetes, known as adult diabetes, is caused by ineffective insulin use by the body. While obesity, sedentary and inactivity and other individual characteristics make diabetic risk factors, the potential role of air pollution has recently been mentioned as an etiological factor affecting these patients' health (Coogan et al. 2016).

Today, in many cities around the world, air pollution has become a peripheral dilemma and its survey is considered as a critical issue in urban management (Delavar et al. 2019). Therefore, given the high air pollution in developing countries, further research is needed on patients with type 2 diabetes (Eze et al. 2015).

In previous studies, the effect of air pollution on the incidence, occurrence, and mortality of type 2 diabetes was studied, and a limited number of studies were undertaken on the effect of air pollution on blood glucose control in type 2 diabetic patients. On the other hand, since blood glucose control is the primary way to prevent common diabetes complications such as heart disease, retinopathy, nephropathy, foot ulcer and amputation (Lucisano et al. 2017), it is crucial to identify the spatial factors affecting these patients' blood glucose control to reduce their complications and costs of treatment.

Environmental pollution is one of the most important risk factors in the spread of diseases (Eze et al. 2015). Inflammation and insulin resistance, which are signs of type 2 diabetes, are associated with exposure to nitrogen dioxide $\left(\mathrm{NO}_{2}\right)$ and fine particulate matter pollutants $\left(\mathrm{PM}_{2.5}\right.$ and $\mathrm{PM}_{10}$ ) (Heidemann et al. 2014, O'Donovan et al. 2017). In an epidemiological study, the trend towards increased risk of insulin resistance, type 2 diabetes, and diabetes-related mortality is generally associated with increased air pollution (Heidemann et al. 2014). In a study in Iran, there was a positive correlation between children's exposure to $\mathrm{PM}_{10}$ and $\mathrm{NO}_{2}$ and insulin resistance (Kelishadi et al. 2009).

The relationship between diabetes prevalence and air pollution has been examined in different studies. Eze et al. (2014) showed that increasing the concentration of the $\mathrm{PM}_{10}$ and $\mathrm{NO}_{2}$ pollutants in the environment by $10 \mu \mathrm{g} / \mathrm{m}^{3}$ is resulted in a 5.5 percent increase in the prevalence of diabetes, which was more clear for the $\mathrm{PM}_{10}$ pollutant. In the afore-mentioned study, pollutant concentrations in participants' residence were assessed by the average levels of pollutants over 10 years (Eze et al. 2014). Eze et al. (2015) showed that a $10 \mu \mathrm{g} / \mathrm{m}^{3}$ increase in $\mathrm{PM}_{2.5}$ and $\mathrm{NO}_{2}$ pollutant concentrations raised the risk of type 2 diabetes by 8 to 10 percent (Eze et al. 2015). Also, Pearson et al. (2010) found a 0.92 percent increase in the prevalence of diabetes associated with a $10 \mu \mathrm{m}$ rise in $\mathrm{PM}_{2.5}$ concentration after adjustment for age, gender, annual income, education level, race, obesity, physical activity, latitude, and population density (Pearson et al. 2010). In another study by Honda et al. (2017), the chances of diabetes prevalence for people exposed to $\mathrm{PM}_{2.5}$ and $\mathrm{NO}_{2}$ pollutants were $35 \%$ and $27 \%$, respectively (Honda et al. 2017).

Park et al. (2015) investigated the long-term effects of exposure to $\mathrm{PM}_{2.5}$ and $\mathrm{NO}$ air pollutants on the prevalence and incidence 
of diabetes in people aged 45-84 years. In this study, the prevalence of diabetes was significantly associated with $\mathrm{PM}_{2.5}$ $(\mathrm{OR}=1.09,95 \% \mathrm{CI}: 1.00,1.17)$ and $\mathrm{NO}(\mathrm{OR}=1.18,95 \% \mathrm{CI}$ : 1.01, 1.38) (Park et al. 2015).

In some studies, the effect of exposure to air pollution on the incidence of diabetes has been investigated. The results obtained by Balti et al. (2016) indicated a significant correlation between pollutants $\left(\mathrm{PM}_{2.5}\right.$ and $\left.\mathrm{NO}_{2}\right)$ and diabetes incidence. The results showed a $13 \%$ and $11 \%$ increase in the rate of diabetes incidence with exposure to $\mathrm{NO} 2$ and $\mathrm{PM}_{2.5}$, respectively (Balti et al. 2014). However, in another study by Park et al. (2015), none of the $\mathrm{PM}_{2.5}$ and $\mathrm{NO}_{2}$ pollutants were associated with diabetes incidence during a 9-year period (Park et al. 2015). The results of the study by Honda et al. (2017) showed that an increased interquartile range in $\mathrm{PM}_{2.5}$ annual average led to a $1.4 \%$ rise in glycosylated haemoglobin (HbA1c) level, while this increase for $\mathrm{NO}_{2}$ was equal to a $2 \%$ rise in $\mathrm{HbA} 1 \mathrm{c}$ level.

In Iran, in 2006, the population of age groups ranging from 50 to 69 years old was equal to $10.36 \%$ and that of for more than 70 years old was $3.49 \%$, which are estimated to be $27.4 \%$ and $7.8 \%$ in 2035, respectively (Aghamohamadi et al. 2018). Most of the reported studies regarding the impact of environmental pollutants on the epidemiology of type- 2 diabetes have been conducted in developed countries (US, Canada, and Europe). With the high rate of type-2 diabetes prevalence in Iran and the country's increasing rate of aging population, as well as the problems of environmental pollutants especially in Tehran (which has a population of 8.3 million), further studies are needed in this regard. In addition, previous studies have examined the effect of air pollution on prevalence, incidence, and mortality of type- 2 diabetes, while few studies have been conducted to monitor this disease and discovering the effective risk factors for controlling blood sugar in these patients. Therefore, investigating the impact of air pollution can play a significant role in controlling type- 2 diabetes and, as a result, reducing its complications and therapeutic costs. Considering the necessity of this issue, we intend to conduct further studies on the effect of air pollutants on blood glucose control in type 2 diabetic patients. The aim of this study is to investigate the effect of exposure to air pollutants $\mathrm{NO}_{2}, \mathrm{PM}_{2.5}$, and $\mathrm{PM}_{10}$ on blood glucose in type 2 diabetic patients in Tehran.

In many studies, serum glucose has been used as a dependent variable to assess the impact of air pollution. Since serum glucose can vary widely over short periods of time, it is not a good idea to consider it as a dependent variable to evaluate the long duration of air pollution. On the other hand, glycosylated haemoglobin, which shows a long-term control of glucose and has a great predictive value for diabetes complications, has been examined in limited studies (ADA, 2018, Liu et al. 2016). Accordingly, in this study, HbA1c values have been used as outcome variables to investigate the effect of exposure to air pollution. Participants included 142 type-2 diabetic patients who were referred to the two Diabetes Clinic and Metabolic Diseases Centers of Endocrines \& Metabolism Research Institute of Tehran University of Medical Sciences.

\section{RESEARCH DESIGN AND METHODS}

\subsection{Participants and Clinical Assessments}

In the present study, the information of 400 patients were collected from the two Diabetes Clinic and
Metabolic Diseases Centers of Endocrines \& Metabolism Research Institute of Tehran University of Medical Sciences, obtained from the patients' medical records in 2016. The input criteria for this study included type 2 diabetic patients and those who have registered their HbAlc values information in their medical records. Type- 1 diabetic or pre-diabetic patients were excluded from our study. Thus, 142 type 2 diabetic patients remained in the study for analysis. Patients' characteristics and air pollution parameters are presented in Table 1 .

\subsection{Clinical measures}

Participant clinical data were collected in 2016 including 3month HbA1c values. Other clinical information includes body mass index (BMI), diabetes duration, information on lifestyle including physical activity and smoking status, demographic information including gender, age, marital status, educational status, and the exact address of patients' residence were also extracted from their medical records.

\begin{tabular}{|c|c|c|c|c|c|}
\hline \multirow{3}{*}{\multicolumn{2}{|c|}{ Characteristics }} & \multicolumn{4}{|c|}{ Gender } \\
\hline & & \multicolumn{2}{|c|}{ Female } & \multicolumn{2}{|c|}{ Male } \\
\hline & & Mean & Count & Mean & Count \\
\hline \multirow{2}{*}{\multicolumn{2}{|c|}{$\begin{array}{l}\text { Age (year) } \\
\text { BMI }\left(\mathrm{kg} / \mathrm{m}^{2}\right)\end{array}$}} & 62 & & 64 & \\
\hline & & 30.33 & 82 & 26.60 & 60 \\
\hline \multicolumn{2}{|c|}{ Diabetes duration (year) } & 14 & 82 & 11 & 60 \\
\hline \multicolumn{2}{|c|}{ HbA1c_Spring (\%) } & 7.39 & 82 & 7.41 & 60 \\
\hline \multicolumn{2}{|c|}{ HbAlc_Summer (\%) } & 7.50 & 82 & 7.62 & 60 \\
\hline \multicolumn{2}{|c|}{ HbA1c_Fall (\%) } & 7.56 & 82 & 7.48 & 60 \\
\hline \multicolumn{2}{|c|}{ HbA1c_Winter (\%) } & 7.21 & 82 & 6.99 & 60 \\
\hline \multirow{3}{*}{ Marital } & Married & & 69 & & 58 \\
\hline & Single & & 5 & & 0 \\
\hline & Divorced & & 7 & & 0 \\
\hline \multirow{3}{*}{$\begin{array}{l}\text { Physical } \\
\text { activity }\end{array}$} & No activity & & 23 & & 16 \\
\hline & Walking & & 29 & & 22 \\
\hline & Exercise & & 10 & & 5 \\
\hline \multirow{3}{*}{ Smoking } & Never & & 70 & & 30 \\
\hline & Former & & 1 & & 13 \\
\hline & Current & & 3 & & 7 \\
\hline \multirow{3}{*}{ Education } & $<$ High school & & 34 & & 7 \\
\hline & Diploma & & 32 & & 25 \\
\hline & Some college & & 10 & & 23 \\
\hline \multirow{3}{*}{ Employment } & Householder & & 60 & & 0 \\
\hline & Retired & & 11 & & 31 \\
\hline & Employee & & 6 & & 24 \\
\hline \multirow{2}{*}{\multicolumn{2}{|c|}{$\begin{array}{ll}\text { Medication } & \text { pills } \\
\text { Insulin + pills }\end{array}$}} & & 52 & & 35 \\
\hline & & & 29 & & 22 \\
\hline \multicolumn{2}{|c|}{$\mathrm{NO}_{2} \_$Spring $\left(\mu \mathrm{g} / \mathrm{m}^{3}\right)$} & 51.35 & 82 & 52.77 & 60 \\
\hline \multicolumn{2}{|c|}{$\mathrm{NO}_{2} \_$Summer $\left(\mu \mathrm{g} / \mathrm{m}^{3}\right)$} & 51.24 & 82 & 53.31 & 60 \\
\hline \multicolumn{2}{|c|}{$\mathrm{NO}_{2} \_$Fall $\left(\mu \mathrm{g} / \mathrm{m}^{3}\right)$} & 54.03 & 82 & 55.90 & 60 \\
\hline \multicolumn{2}{|c|}{$\mathrm{NO}_{2} \_$Winter $\left(\mu \mathrm{g} / \mathrm{m}^{3}\right)$} & 61.16 & 82 & 63.83 & 60 \\
\hline \multicolumn{2}{|c|}{$\mathrm{PM}_{2.5}$ _Spring $\left(\mu \mathrm{g} / \mathrm{m}^{3}\right)$} & 19.35 & 82 & 21.18 & 60 \\
\hline \multicolumn{2}{|c|}{$\mathrm{PM}_{2.5}$ Summer $\left(\mu \mathrm{g} / \mathrm{m}^{3}\right)$} & 20.72 & 82 & 22.90 & 60 \\
\hline \multicolumn{2}{|c|}{$\mathrm{PM}_{2.5}$ Fall $\left(\mu \mathrm{g} / \mathrm{m}^{3}\right)$} & 26.63 & 82 & 28.68 & 60 \\
\hline \multicolumn{2}{|c|}{$\mathrm{PM}_{2.5}$ _Winter $\left(\mu \mathrm{g} / \mathrm{m}^{3}\right)$} & 50.10 & 82 & 52.79 & 60 \\
\hline \multicolumn{2}{|c|}{$\mathrm{PM}_{10 \_ \text {Spring }}\left(\mu \mathrm{g} / \mathrm{m}^{3}\right)$} & 74.22 & 82 & 72.97 & 60 \\
\hline \multicolumn{2}{|c|}{$\mathrm{PM}_{10}$ Summer $\left(\mu \mathrm{g} / \mathrm{m}^{3}\right)$} & 102.7 & 82 & 101.9 & 60 \\
\hline \multicolumn{2}{|c|}{ PM10_Fall $\left(\mu \mathrm{g} / \mathrm{m}^{3}\right)$} & 96.22 & 82 & 95.22 & 60 \\
\hline $\mathrm{PM}_{10 \_ \text {Winter }}$ & $\mathrm{r}\left(\mu \mathrm{g} / \mathrm{m}^{3}\right)$ & 105.8 & 82 & 104.7 & 60 \\
\hline
\end{tabular}

Abbreviations: Std.: Standard Deviation, BMI: body mass index, $\mathrm{NO}_{2}$ : Nitrogen dioxide, $\mathrm{PM}_{2.5}$ : particulate matter 2.5, $\mathrm{PM}_{10}$ : particulate matter 10 HbA1c: glycosylated haemoglobin

Table 1. Patients' and air pollution's characteristics 


\subsection{Study Area}

The area under study is Tehran District 6 with south western geographical location including Lon. $=51.38$ and Lat. $=35.7$ and northeast with Lon. $=51.42$ and Lat. $=35.75$ and $21.7 \mathrm{~km}^{2}$ area is considered as the central regions of Tehran city. The addresses of all patients were geocoded on the map (Figure 1).

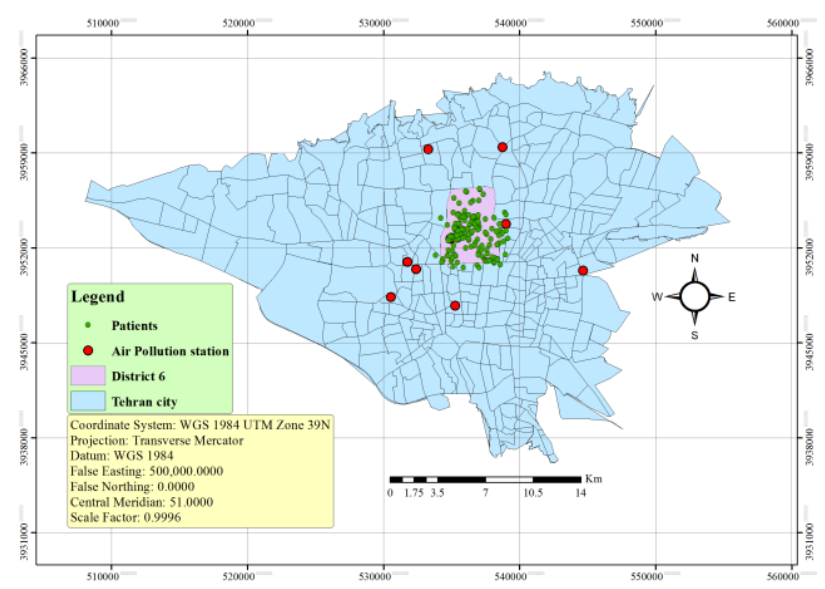

Figure 1. Case study and air pollution stations

\subsection{Assessment of Exposure to Air Pollutants}

Data on average daily levels of $\mathrm{NO}_{2}, \mathrm{PM}_{2.5}$, and $\mathrm{PM}_{10}$ air pollutants were collected from Tehran Municipality's Air Quality Control website (www.air.tehran.ir) for 9 stations around District 6 of Tehran (Figure 1) over one year from March 20, 2016, to March 20, 2017. Because of the existence of only one air pollution station in our study area, we used the model of air pollution prediction employed in Delavar et al. (2019) to estimate the pollutants in patients' residence. In this model, the elements of weather (wind speed and direction, minimum and maximum temperature, humidity), topography (X, Y, Z), weekdays and months of the year are used as predictor variables.

Since $\mathrm{NO}_{2}$ air pollution is an essential gas pollutant in road traffic (Recio et al. 2016), we used the element of the area of streets in a 250-meter buffer to improve the estimation of pollutants. On the other hand, as the distance from the highway is used as an independent spatial pollutant predictor (Liang et al. 2018), we used the distance from the highway as another effective element in the estimation of pollutants. Then, the quarterly average of each pollutant was calculated in order to measure the exposure to air pollution for all participants' residences.

\subsection{Statistical Analysis}

Partial correlations have been employed to determine the correlations between air pollutants of $\mathrm{NO}_{2}, \mathrm{PM}_{2.5}$, and $\mathrm{PM}_{10}$ and HbAlc values of type 2 diabetic patients. Based on air pollutant quartiles and HbA1c quartiles, the Odds Ratio (OR) for the classified groups were calculated by considering the lowest quartile of the slight pollutant as the reference for exposure to the least air pollution. Furthermore, the one-way analysis of variance (ANOVA) was used to investigate the difference between $\mathrm{HbA1c}$ averages in quartiles of pollutants.

\section{RESULTS}

In Table 2, statistics of $F=3.29$ indicates a significant difference of $\mathrm{HbA1c}$ between groups at a confidence level of 95\%. Therefore, $\mathrm{NO}_{2}$ pollutant increase was faced with a significant increase in the mean difference of $\mathrm{HbAlc}$ between groups in $\mathrm{NO}_{2}$ quartiles in the female group (Figure 2). In Figure 2, the $\mathrm{x}$ and the $\mathrm{y}$-axes represent $\mathrm{NO}_{2}$ quartiles and the mean of $\mathrm{HbA} 1 \mathrm{c}$ in each group.

\begin{tabular}{|l|c|c|c|c|}
\hline & df & Mean Square & F & Sig. \\
\hline Between Groups & 3 & 5.58 & 3.29 & 0.026 \\
Within Groups & 64 & 1.69 & & \\
Total & 67 & & & \\
\hline
\end{tabular}

Abbreviations: df: degree of freedom, Sig.: significance

Table 2. ANOVA test

Partial correlations between $\mathrm{HbA} 1 \mathrm{c}$ and $\mathrm{NO}_{2}$ pollutant after adjustment for control variables of age, duration of diabetes and BMI by gender segregation were significant just for women group with a correlation coefficient of 0.434 ( $\mathrm{p}$-value $<0.001$ ) at $99 \%$ confidence level (Table 3). The results showed that women in the highest quartile of $\mathrm{NO}_{2}$ air pollution in their residence had a tendency to higher levels of HbA1c compared to women in the lower quartile.

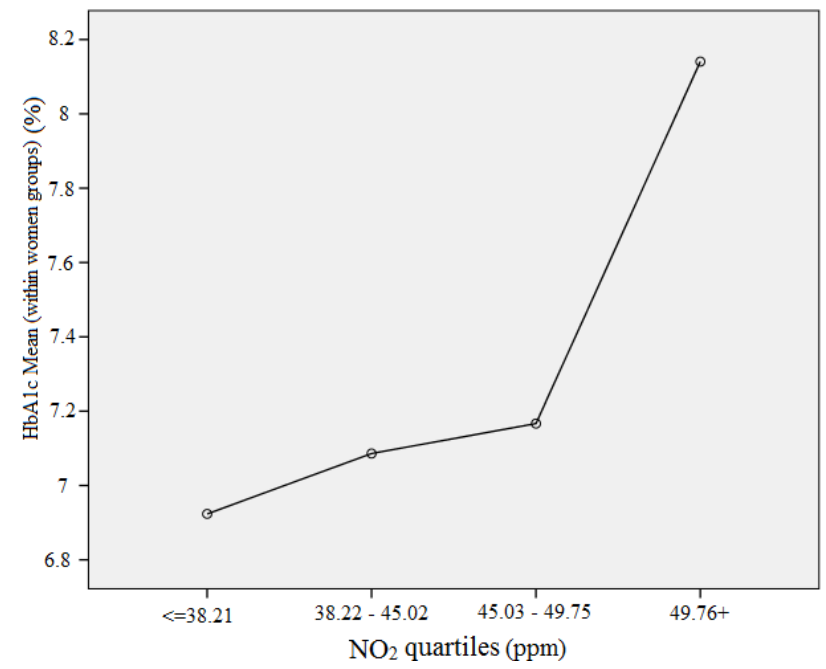

Figure 2. Mean plot into $\mathrm{NO}_{2}$ quartiles

\begin{tabular}{|lc|c|c|c|c|}
\hline Gender & $\begin{array}{c}\mathrm{NO}_{2} \\
\text { Spring }\end{array}$ & $\begin{array}{c}\mathrm{NO}_{2} \\
\text { Summer }\end{array}$ & $\begin{array}{c}\mathrm{NO}_{2} \\
\text { Fall }\end{array}$ & $\begin{array}{c}\mathrm{NO}_{2} \\
\text { Winter }\end{array}$ \\
\hline \multirow{2}{*}{ Female } & Correlation & $0.43^{*}$ & $0.40^{*}$ & $0.32^{*}$ & 0.24 \\
& Sig. (2-tailed) & 0.00 & 0.00 & 0.01 & 0.10 \\
Male & Correlation & -0.06 & 0.01 & -0.02 & -0.28 \\
& Sig. (2-tailed) & 0.67 & 0.93 & 0.86 & 0.10 \\
\hline Control variables: Age, BMI and DD \\
Dependent variable: HbA1c \\
Abbreviations: DD: diabetes duration, BMI: body mass index, \\
NO ${ }_{2}$ : nitrogen dioxide, HbA1c: glycosylated haemoglobin, \\
Sig.: significance \\
\hline
\end{tabular}

Table 3. Partial correlation results between $\mathrm{HbA} 1 \mathrm{c}$ and $\mathrm{NO}_{2}$ pollutant 


\begin{tabular}{|c|c|c|c|c|c|c|c|c|}
\hline \multicolumn{9}{|c|}{$\mathrm{NO}_{2} \_$Spring $* \mathrm{HbA} 1 \mathrm{c}$ Cross-tabulation } \\
\hline \multirow{2}{*}{\multicolumn{4}{|c|}{ Gender: female }} & \multicolumn{4}{|c|}{ HbA1c (quartiles) (\%) } & \multirow[b]{2}{*}{ Total } \\
\hline & & & & $\leq 6.30$ & $6.31-6.95$ & $\begin{array}{c}6.96- \\
8.15\end{array}$ & $\geq 8.16$ & \\
\hline \multirow{10}{*}{$\begin{array}{c}\mathrm{NO}_{2} \\
\left(\mu \mathrm{g} / \mathrm{m}^{3}\right)\end{array}$} & \multirow{10}{*}{ 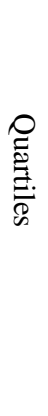 } & \multirow{2}{*}{$\leq 38.21$} & Count & 5 & 3 & 8 & 1 & 17 \\
\hline & & & $\%$ within $\mathrm{NO}_{2}$ & $29.4 \%$ & $17.6 \%$ & $47.1 \%$ & $5.9 \%$ & $100.0 \%$ \\
\hline & & \multirow{2}{*}{$38.22-45.02$} & Count & 9 & 4 & 3 & 4 & 20 \\
\hline & & & $\%$ within $\mathrm{NO}_{2}$ & $45.0 \%$ & $20.0 \%$ & $15.0 \%$ & $20.0 \%$ & $100.0 \%$ \\
\hline & & \multirow{2}{*}{$45.03-49.75$} & Count & 4 & 3 & 2 & 3 & 12 \\
\hline & & & $\%$ within $\mathrm{NO}_{2}$ & $33.3 \%$ & $25.0 \%$ & $16.7 \%$ & $25.0 \%$ & $100.0 \%$ \\
\hline & & \multirow{2}{*}{$\geq 49.76$} & Count & 1 & 5 & 4 & 9 & 19 \\
\hline & & & $\%$ within $\mathrm{NO}_{2}$ & $5.3 \%$ & $26.3 \%$ & $21.1 \%$ & $47.4 \%$ & $100.0 \%$ \\
\hline & & \multirow{2}{*}{ Total } & Count & 19 & 15 & 17 & 17 & 68 \\
\hline & & & $\%$ within $\mathrm{NO}_{2}$ & $27.9 \%$ & $22.1 \%$ & $25.0 \%$ & $25.0 \%$ & $100.0 \%$ \\
\hline
\end{tabular}

Table 4. Cross tabulation for $\mathrm{NO}_{2}$ and $\mathrm{HbAlc}$

\begin{tabular}{|c|c|c|c|c|}
\hline \multicolumn{5}{|c|}{$\mathrm{NO}_{2}$ (Spring) } \\
\hline & $<=38.21$ & $38.22-45.02$ & $45.03-49.75$ & $49.76+$ \\
& $\mathrm{N}=17$ (reference) & $\mathrm{N}=20$ & $\mathrm{~N}=12$ & $\mathrm{~N}=19$ \\
\hline \multirow{2}{*}{ OR } & 1 & 2.2 & 3.75 & 45 \\
& 1 & $(95 \%$ CI: $0.19-25.7)$ & $(95 \%$ CI: $0.27-51.4)$ & $(95 \%$ CI: $2.3-885.6)$ \\
\hline \multicolumn{4}{|l}{ Abbreviations: $\mathrm{NO}_{2}$ : nitrogen dioxide, OR: odds ratio } \\
\hline
\end{tabular}

Table 5. Odds ratio results for women in exposure to $\mathrm{NO}_{2}$ air pollution

\begin{tabular}{|c|c|c|c|}
\hline \multicolumn{3}{|c|}{ NO2 (Summer) } \\
\hline & $\mathrm{N}=22$ (reference) & $37.86-50.30$ & $50.31+$ \\
& 1 & $\mathrm{~N}=22$ & $\mathrm{~N}=21$ \\
\hline OR & 1 & $2.18(95 \%$ CI: $0.47-10)$ & $5(95 \%$ CI: $1.03-24.28)$ \\
\hline \multicolumn{2}{|l}{ Abbreviations: $\mathrm{NO}_{2}$ : nitrogen dioxide, OR: odds ratio } \\
\hline
\end{tabular}

Table 6. Odds ratio results for women in exposure to $\mathrm{NO}_{2}$ air pollution

The odds ratio (OR) for $\mathrm{NO}_{2}$ pollutant was calculated through cross-tabulation (Table 4). As shown in Tables 5 and 6, the odds ratio for $\mathrm{NO}_{2}$ pollutant represents a $45 \%$ and $5 \%$ increase in patients' $\mathrm{HbAlc}$ levels with a $12-\mu \mathrm{g} / \mathrm{m}^{3}$ rise in average nitrogen dioxide concentration at their residence in spring (OR: 45; 95\% CI: 2.28 - 885.6) and summer (OR: 5; 95\% CI: 1.03 24.28), respectively.

According to Table 7, partial correlations between HbA1c and $\mathrm{PM}_{2.5}$ pollutants after adjustment for control variables of age, duration of diabetes, and BMI in gender segregation only for women were significant with a correlation coefficient of 0.27 (p-value $=0.033)$, but the odds ratio for this pollutant was not significant at $95 \%$ confidence level. Also, the results of the survey of the correlation between $\mathrm{HbA} 1 \mathrm{c}$ and $\mathrm{PM}_{10}$ pollutant were not significant for none of women and men groups.

\begin{tabular}{|lc|c|c|c|c|}
\hline \multirow{2}{*}{ Gender } & & $\mathrm{PM}_{2.5}$ & $\mathrm{PM}_{2.5}$ & $\mathrm{PM}_{2.5}$ & $\mathrm{PM}_{2.5}$ \\
& & Spring & Summer & Fall & Winter \\
\hline \multirow{2}{*}{ Female } & Correlation & $0.27 *$ & 0.09 & -0.11 & 0.17 \\
& Sig. (2-tailed) & 0.03 & 0.49 & 0.37 & 0.23 \\
\multirow{2}{*}{ Male } & Correlation & -0.16 & -0.059 & -0.13 & 0.03 \\
& Sig. (2-tailed) & 0.23 & 0.66 & 0.38 & 0.85 \\
\hline
\end{tabular}

Control variables: Age, BMI and diabetes duration Dependent variable: HbA1c

Abbreviations: BMI: body mass index, Sig.: significance

Table 7. Partial correlation results between $\mathrm{HbA} 1 \mathrm{c}$ and $\mathrm{PM}_{2.5}$ pollutant

\section{CONCLUSIONS}

Given the development of advanced data collection technologies (e.g., biosensors and GPS), effective parameters (specifically, spatially factors) need to be identified in order to improve the decision-making process by knowing these parameters and determining the type and severity of their impact to take appropriate decisions on blood glucose control. To achieve this goal, we looked at the impact of air pollution and its severity on diabetic blood glucose control.

The results of this study confirm the correlation between exposure to $\mathrm{NO}_{2}$ and $\mathrm{PM}_{2.5}$ and blood glucose in type 2 diabetic patients. The results obtained by Honda et al. (2017) also showed a rise of $1.4 \%$ and $2 \%$ in HbA1c levels with exposure to an increased interquartile range in annual average values of $\mathrm{PM}_{2.5}$ and $\mathrm{NO}_{2}$, respectively (Honda et al. 2017). Also, a study by Chuang et al. in 2010 showed that exposure to air pollution $(\mathrm{PM} \leq 10 \mu \mathrm{m})$ leads to a change in HbA1c (Chuang et al. 2010).

Additionally, according to our results in this research, exposure to $\mathrm{NO}_{2}$ and $\mathrm{PM}_{2.5}$ air pollutants for type 2 diabetic women affects their glucose control and can come to attention in the development of spatial decision support systems (SDSS). Similar findings in two studies on $\mathrm{PM}_{2.5}$ and $\mathrm{NO}_{2}$ also reported a stronger correlation between air pollution and type- 2 diabetes in women compared to men (Pedersen et al. 2017, Eze et al. 2015). 
The strength of this research is to use the accurate model for prediction of air pollution (RMSE $=1.79 \mu \mathrm{g} / \mathrm{m}^{3}$ ) and to use elements of distance to highways and the area of streets around the patient's residence to improve the estimation of pollutants. The weakness of this research is its low sample size to achieve more statistically sound results.

Finally, according to our results, we suggested that air pollution could be considered as one of the effective potential predictor variables, especially for women, to decide to conduct a blood glucose control system for type 2 diabetic patients.

\section{REFERENCES}

Aghamohamadi, S., K. Hajinabi, K. Jahangiri, I. M. Asl and R. J. E. M. h. j. Dehnavieh. Population and mortality profile in the Islamic Republic of Iran, 2006-2035, 2018 24(5): 469-476.

Balti, E. V., J. B. Echouffo-Tcheugui, Y. Y. Yako, A. P. J. D. r. Kengne and c. practice. Air pollution and risk of type 2 diabetes mellitus: a systematic review and meta-analysis, 2014 106(2): 161-172.

care, A. D. A. J. D., 6. Glycemic targets: standards of medical care in diabetes-2018, 2018 41(Supplement 1): S55-S64.

Chuang, K.-J., Y.-H. Yan, T.-J. J. J. o. o. Cheng and e. medicine."Effect of air pollution on blood pressure, blood lipids, and blood sugar: a population-based approach, 2010 52(3): 258-262.

Coogan, P. F., L. F. White, J. Yu, R. T. Burnett, J. D. Marshall, E. Seto, R. D. Brook, J. R. Palmer, L. Rosenberg and M. J. E. r. Jerrett, Long term exposure to NO2 and diabetes incidence in the Black Women's Health Study, 2016, 148: 360-366.

Delavar, M. R., A. Gholami, G. R. Shiran, Y. Rashidi, G. R. Nakhaeizadeh, K. Fedra and S. J. I. I. J. o. G.-I. Hatefi Afshar. A Novel Method for Improving Air Pollution Prediction Based on Machine Learning Approaches: A Case Study Applied to the Capital City of Tehran, 2019, 8(2): 99.

Eze, I. C., L. G. Hemkens, H. C. Bucher, B. Hoffmann, C. Schindler, N. Künzli, T. Schikowski and N. M. J. E. h. p. Probst-Hensch. Association between ambient air pollution and diabetes mellitus in Europe and North America: systematic review and meta-analysis, 2015, 123(5): 381-389.

Eze, I. C., E. Schaffner, E. Fischer, T. Schikowski, M. Adam, M. Imboden, M. Tsai, D. Carballo, A. von Eckardstein and N. J. E. i. Künzli. Long-term air pollution exposure and diabetes in a population-based Swiss cohort, 2014 70: 95-105.

Heidemann, C., H. Niemann, R. Paprott, Y. Du, W. Rathmann and C. J. D. M. Scheidt-Nave. Residential traffic and incidence of type 2 diabetes: the German Health Interview and Examination Surveys, 2014, 31(10): 1269-1276.

Honda, T., V. C. Pun, J. Manjourides, H. J. I. j. o. h. Suh and e. health. Associations between long-term exposure to air pollution, glycosylated hemoglobin and diabetes, 2017, 220(7): 1124-1132.
Kelishadi, R., N. Mirghaffari, P. Poursafa and S. S. J. A. Gidding. Lifestyle and environmental factors associated with inflammation, oxidative stress and insulin resistance in children, 2009, 203(1): 311-319.

Liang, D., R. Golan, J. L. Moutinho, H. H. Chang, R. Greenwald, S. E. Sarnat, A. G. Russell and J. A. J. E. r. Sarnat. Errors associated with the use of roadside monitoring in the estimation of acute traffic pollutant-related health effects, 2018, 165: 210-219.

Liu, C., C. Yang, Y. Zhao, Z. Ma, J. Bi, Y. Liu, X. Meng, Y. Wang, J. Cai and H. J. E. i. Kan. Associations between longterm exposure to ambient particulate air pollution and type 2 diabetes prevalence, blood glucose and glycosylated hemoglobin levels in China, 2016, 92: 416-421.

O'Donovan, G., Y. Chudasama, S. Grocock, R. Leigh, A. M. Dalton, L. J. Gray, T. Yates, C. Edwardson, S. Hill and J. J. E. i. Henson. The association between air pollution and type 2 diabetes in a large cross-sectional study in Leicester: The CHAMPIONS Study, 2017, 104: 41-47.

Park, S. K., S. D. Adar, M. S. O'Neill, A. H. Auchincloss, A. Szpiro, A. G. Bertoni, A. Navas-Acien, J. D. Kaufman and A. V. J. A. j. o. e. Diez-Roux. Long-term exposure to air pollution and type 2 diabetes mellitus in a multiethnic cohort, 2015, 181(5): $327-336$

Pearson, J. F., C. Bachireddy, S. Shyamprasad, A. B. Goldfine and J. S. J. D. c. Brownstein. Association between fine particulate matter and diabetes prevalence in the US, 2010, 33(10): 2196-2201.

Pedersen, M., S. F. Olsen, T. I. Halldorsson, C. Zhang, D. Hjortebjerg, M. Ketzel, C. Grandström, M. Sørensen, P. Damm and J. J. E. i. Langhoff-Roos. Gestational diabetes mellitus and exposure to ambient air pollution and road traffic noise: A cohort study, 2017, 108: 253-260.

Recio, A., C. Linares, J. R. Banegas and J. J. E. r. Díaz. The short-term association of road traffic noise with cardiovascular, respiratory, and diabetes-related mortality, 2016, 150: 383-390. 